\title{
Article \\ Objective Method for Determining the Importance of Unprecedented Restlessness as a Rice Crisis Indicator at the National Level
}

\author{
Yuyun Hidayat ${ }^{1, *}$, Titi Purwandari ${ }^{1}$, Dewi Ratnasari ${ }^{2}$, Sukono ${ }^{3}$, Jumadil Saputra ${ }^{4}(-)$ and Subiyanto ${ }^{5}(\mathbb{C}$ \\ 1 Department of Statistics, Faculty of Mathematics and Natural Sciences, Universitas Padjadjaran Sumedang, \\ Bandung 45363, Indonesia; titipurwandari@yahoo.com \\ 2 Department of Chinese Language and Cultural Studies, Faculty of Cultural Sciences, \\ Universitas Padjadjaran Sumedang, Bandung 45363, Indonesia; dewi.ratnasari@unpad.ac.id \\ 3 Department of Mathematics, Faculty of Mathematics and Natural Sciences, \\ Universitas Padjadjaran Sumedang, Bandung 45363, Indonesia; sukono@unpad.ac.id \\ 4 School of Social and Economic Development, Universiti Malaysia Terengganu, Kuala Terenggan 21300, Kuala \\ Nerus, Terengganu, Malaysia; jumadil.saputra@umt.edu.my \\ 5 Department of Marine Science, Faculty of Fishery and Marine Science, Universitas Padjadjaran, \\ Bandung 45363, Indonesia; subiyanto@unpad.ac.id \\ * Correspondence: yuyun.hidayat@unpad.ac.id
}

check for

updates

Citation: Hidayat, Y.; Purwandari, T.; Ratnasari, D.; Sukono; Saputra, J.; Subiyanto. Objective Method for Determining the Importance of Unprecedented Restlessness as a Rice Crisis Indicator at the National Level. Agronomy 2021, 11, 1195.

https://doi.org/10.3390/ agronomy11061195

Academic Editor: Thomas Bournaris

Received: 1 May 2021

Accepted: 8 June 2021

Published: 11 June 2021

Publisher's Note: MDPI stays neutral with regard to jurisdictional claims in published maps and institutional affiliations.

Copyright: (c) 2021 by the authors. Licensee MDPI, Basel, Switzerland. This article is an open access article distributed under the terms and conditions of the Creative Commons Attribution (CC BY) license (https:// creativecommons.org/licenses/by/ $4.0 /)$.
Abstract: In this study, we use restlessness as an input for a rice crisis indicator, since restlessness rather than rice price provides a comparable year-to year context. We outline the significant increase in the use of unprecedented restlessness (UR) as an indicator for rice crises. The UR approach involves a precedence analysis, in contrast with the existing approach, the price shock analysis. We test UR as a new indicator for rice crises at the national level, which can be applied in Asia and other countries around the world where rice is the staple food. Strong indicators point out the effectiveness of strategic government programs and are able to assess solutions and detect rice crises, while weak indicators are only reliable in detecting whether or not there has been a crisis. UR is tested across 43 countries using two new statistics: success probability (SP) and constraint probability (CP). As a consequence of SP and CP calculations, a large number of IMR control charts for UR analysis are constructed to provide evidence that UR is a strong indicator. The optimum validity measurement result is achieved with $\mathrm{SP}=8 / 26=0.31$ and $\mathrm{CP}=8 / 14=0.57$. This means that the UR detects and is followed by only $31 \%$ of riot events. Since the value of SP is less than 0.6 , we can conclude that the UR indicator is not considered valid as an indicator of rice crises at the national level. The values of $\mathrm{CP}$ and SP are determined subjectively as equal to 0.6. This is the main cause of the emergence of new problems in the calibration of UR as an indicator of rice crises. The subjective success criteria trigger a question regarding why the value is 0.6 , for which there is no scientific justification. Based on this background, we continue to objectively establish success criteria for UR validity. After conducting a risk analysis involving a crisis recovery cost (CRC) to crisis anticipation cost (CAC) ratio, it is found that the probability of the CRC-to-CAC ratio having values greater than 7 is 0.76 , which means the CRC-to-CAC ratio tends to be higher than 7. Objectively, it is concluded that UR, which has been defined as rice crisis indicator at the national level, is an important indicator.

Keywords: crisis recovery cost (CRC); crisis anticipation cost (CAC) ratio; objective success criteria; risk analysis

\section{Introduction \\ 1.1. Definition of Rice Crisis}

Although the concept of food security now has a widely accepted definition-namely that "food security exists when all people have physical and economic access to sufficient, safe, and nutritious food for a healthy and active life", both the Food and Agriculture 
Organization (FAO) and the UN World Food Program (WFP) differentiate transitory from chronic food insecurity and talk specifically of "crisis-induced food insecurity" [1]. However, the WFP Strategic Plan contains not even a single mention of the term food crisis. Instead, the plan speaks of emergencies, defined "as urgent situations in which there is clear evidence that an event or series of events has occurred which causes human suffering or imminently threatens human lives or livelihoods and which the government concerned has not the means to remedy; and it is a demonstrably abnormal event or series of events which produces dislocation in the life of a community on an exceptional scale" [2]. In monitoring such emergencies, the WFP uses indicators of mortality rates, nutrition, and food security, but warns that contextual and qualitative information should always be used to support an analysis [3]. The Integrated Food Security Phase Classification (IPC) was originally developed in Somalia under the FAO Food Security and Nutrition Analysis Unit (FSNAU), which states that an area is in crisis (or phase 3) when "at least one in five households in the area have the following or worse: food consumption gaps with high or above usual acute malnutrition; or are marginally able to meet minimum food needs only with accelerated depletion of livelihood assets that will lead to food consumption gaps" [4]. In fact, the World Bank's Operational Manual 8.00 [5] does not differentiate between crises and emergencies, and also uses the term disaster in stating when the bank can respond to a borrower's request for assistance, which is in "an event that has caused, or is likely to imminently cause, a major adverse economic or social impact associated with natural or man-made crises or disasters" [6]. Circumscribing the analysis to individual staple food prices (rather than domestic food inflation) is not ideal. It is well known that the consumption of staples is subject to substitution, typically for cheaper staples or for non-staples, as prices go up [7]. The European Commission specifically defines a food crisis as "a humanitarian crisis arising from inadequate food consumption, poor food utilization, or high prevalence of acute malnutrition" (European Commission, 2010, 28). Finally, the UN International Strategy for Disaster Reduction (UNISDR) discusses disasters that affect food security; however, its Strategic Framework 2025 does not mention food crisis [8]. This cursory review of the concept of a food crisis shows key agencies failing to adopt a common definition for such a crisis. Agencies either adopt a relatively vague definition that includes both causes (such as floods or economic collapse) and symptoms (threat to human lives or disruption of livelihoods) or use past and current evidence to inform a judgment. Most approaches emphasize the abnormal nature of a crisis, even when notions of normality and severity may not be clearly defined. In practice, this lack of a common and specific definition provides limited grounds for analysis, preventive action, and timely collective action by the international community [9]. Furthermore, different analyses of the severity and nature of a crisis may spur not only different response timings, but also different types of responses based on whether the crisis is considered chronic, transitory, or cyclical and whether it is considered severe or moderately serious [10].

\subsection{The New Rice Crisis Definitions}

This paper starts by zeroing in on the definition—or the lack of a consensus on the definition - of a rice crisis and the operational properties of the timeliness, coverage, and scope of the most prominent rice crisis monitoring systems currently in place.

A rice crisis is defined as a situation in which a prolonged uncontrollable riot occurs because of rice scarcity [11]. This definition succinctly describes a crisis as a situation in which intolerable bad things happen [11], with an emphasis on the word intolerable. What are these uncontrollable riots that we are so afraid of? The suggested riot scaling systems have not yet been accepted globally. However, there were horrific food-related riots in 2008 that received global attention. The severity of the situation during those years was widely reported. A summary report of food riots that erupted across the globe in 2008 outlined state responses to the food riots and highlighted the state of democracy in countries where the riots occurred [12]. This condition, therefore, caused the perception that the riots happening in 2008 were prolonged and uncontrollable. 


\subsection{The Model: Unprecedented Restlessness (UR) as a New Strong Indicator for Rice Crises}

In an effort to give policymakers of food crisis alerts, the IFPRI developed a new tool that measures excessive food price variability, providing an early warning system to alert the world to price abnormalities for rice in the global agricultural markets, meaning policymakers can make better informed plans and decisions, including when to release rice stocks from emergency reserves [13]. This framework is focused on price and does not examine other factors that govern food crises [14]. Development does not define the duration of a food crisis, but rather defines operational indicators that can monitor how close food prices are to the categorized crisis level. The weakness of the monitoring framework proposed by the World Bank and IFPRI above is that even though a rice price hike may never occur, we may still see a rice crisis; similarly, although no natural disaster may occur, we may still see a rice crisis caused by mismanagement. Rice crises will occur sooner or later, even in the absence of a global price shock. To overcome the weakness of the models studied here, we propose a different approach, called the unprecedented restlessness rice crisis indicator.

Why did people take part in the 2008 riots? In general, people riot because they feel restless. They feel restless when their life burden becomes heavier. However, this life burden is likely to change, and such change is expected to be unfavorable to people because supplies will increase arithmetically while consumption will increase geometrically [15]. People rioted uncontrollably in 2008 because they felt an extraordinary burden. This burden had no precedence and was, therefore, unprecedented. This unprecedented burden led to unprecedented restlessness and eventually forced people to riot uncontrollably. The procedures for establishing correct, valid, and reliable models are the main problems involved in modeling [16], and the modeling of new rice crisis indicators is no exception.

Yuyun et al. (2015) developed a restlessness ratio to quantify the burden of life, involving the concept of a rice-related restlessness ratio to quantify the life burden in a rice affordability context at the national level [11]. The rice-price-to-income ratio is the key indicator for rice affordability, as it shows a nation's costs in relation to its income. The ratio clearly shows that the lower the price is, the more affordable the rice will be. Changes in the ratio can also highlight potential problems-if the ratio increases from one period to the next, this means that prices are increasing at a higher rate than income. A strong rice price increase may cause more suffering for low-income households. Logically, an increase in the rice price is equivalent to a drop in real income for the majority of the poor people who are net consumers of rice, meaning the rice-price-to-income ratio will increase significantly. In this context, higher prices increase the number of poor people and push these people deeper into poverty and hunger, forcing them to sacrifice essentials such as more nutritious food, health care, and their children's education.

A mathematical expression for the rice-related restlessness ratio $(\mathrm{R})$ as the ratio between the price and per capita income is shown in Equation (1):

$$
\mathrm{R}=\frac{P}{I}
$$

where $P$ is the rice price (USD/Kilogram) and $I$ is the income per capita (GNI USD per capita).

In this study, we improve the R formula by changing Equation (1) to Equation (2).

$$
\mathrm{R}=\frac{P}{I} * C
$$

It is important to note that in Equation (2), the $C$ variable is added, with $C$ representing rice consumption ( $\mathrm{kg} /$ capita).

The $C$ variable was added because the assumption of constant consumption per year in Equation (1) is not realistic, since population growth occurs every year. This means the consumption of rice will be different every year. If rice consumption is low then the 
burden of life related to obtaining the rice will be low (and even lower for those who do not consume rice).

In addition, Equation (2) improves on Equation (1), making R become dimensionless, which is the one thing that is not done in Equation (1). Another weakness of $\mathrm{R}$ in Equation (1) is that it does not measure the adequacy of income in meeting the energy needs per capita/year.

\subsection{Validity of the Model}

To measure the level of validity of the unprecedented restlessness indicator, calculation of the success probability and constraint probability is required. Both must show values greater than or equal to $60 \%$. This step is used in this study as a calibration tool. The success probability (SP) and constraint probability (CP) indicators were developed as accuracy measurements of the validity, using the same process as the "confusion matrix" theory to measure the accuracy, which is commonly used in data mining classification processes [17]. In the field of machine learning, and specifically the problem of statistical classification, a confusion matrix, also known as an error matrix, is a specific table layout that allows visualization of the performance of an algorithm, typically a supervised learning algorithm (in unsupervised learning, it is usually called a matching matrix) [18]. Each row of the matrix represents the instances in a predicted class, while each column represents the instances in an actual class (or vice versa) [19]. According to Chicco and Jurman, the most informative MI chart metric for evaluating a confusion matrix is the Matthews correlation coefficient (MCC) [20].

A validity measurement is conducted by implementing the control chart concept. The accuracy of the control chart is evaluated using the success probability (SP) and constraint probability (CP) instead of using the G-index [21]. The process of comparing the predicted results with the actual data is performed to measure whether the predictor, indicator, or classifier can "guess correctly" or not. The comparative results are summarized into a confusion matrix, namely a $2 \times 2$ contingency table called the Ry table as shown in Table 1 .

Table 1. The $2 \times 2$ contingency table (Ry).

\begin{tabular}{cccc}
\hline & Unprecedented & Non Unprecedented & Total \\
\hline Crisis & $\mathrm{a}$ (True Positive) & $\mathrm{b}$ (False Positive) & $\mathrm{R} 1$ \\
\hline No Crisis & $\mathrm{c}$ (False Negative) & $\mathrm{d}$ (True Negative) & $\mathrm{R} 2$ \\
\hline Total & $\mathrm{C} 1$ & $\mathrm{C} 2$ & $\mathrm{~N}$ \\
\hline
\end{tabular}

a: number of unprecedented events that match the crisis event; b: number of expected events that match the crisis event; c: number of unprecedented that events match the non-crisis event; $d$ : number of expected events that match the non-crisis event; R1: $a+b$ (number of crisis events); R2: $c+d$ (number of non-crisis events); 1 : $a$ $+c$ (number of unprecedented events); $C 2: b+d$ (number of expected events); $N$ : number of observation year (check year).

The parameters in the Ry table are explained in the following example.

Restlessness, R, is calculated using Equation (1). N unprecedented restlessness analysis is performed using the IMR control chart. The detection of unprecedented restlessness is done by analyzing restless data. The analysis begins with the three year moving average $R(3)$ and ends with the $N$ year moving average $R(N)$. The length of the moving average depends on the data availability for each country. In this case, if the value of $R$ falls within the control limits, this means that the unprecedented event has not been identified. In order to check the strong indicator properties of unprecedented restlessness, two questions must be answered, namely whether the process is in control and whether the process is in crisis state. There are four answers or four cells: out of control and crisis, in control and crisis, out of control and no crisis, in control and no crisis.

If we consider Figure 1, the three points are within control limits, so they are stated as being in control. If we check the presence of rice crises in 2000, 2001, and 2002, we can see that there were no rice crises for these 3 years in the Philippines, meaning these three 
years are included in the "in control and no crisis" cell. Different events occur in Figure 2. It can be noted that one point from sample R(9) in the year 2006 is plotted above the upper control limits, meaning the restless data are out of control and unprecedented restlessness is detected $(\mathrm{V})$. In that year, there was a rice crisis incident, meaning that this observation is included in the "out of control and crisis" cell. A similar process is performed for all countries by constructing a control chart, as presented in Figures 1 and 2, which summarize the results shown in Table 2 .

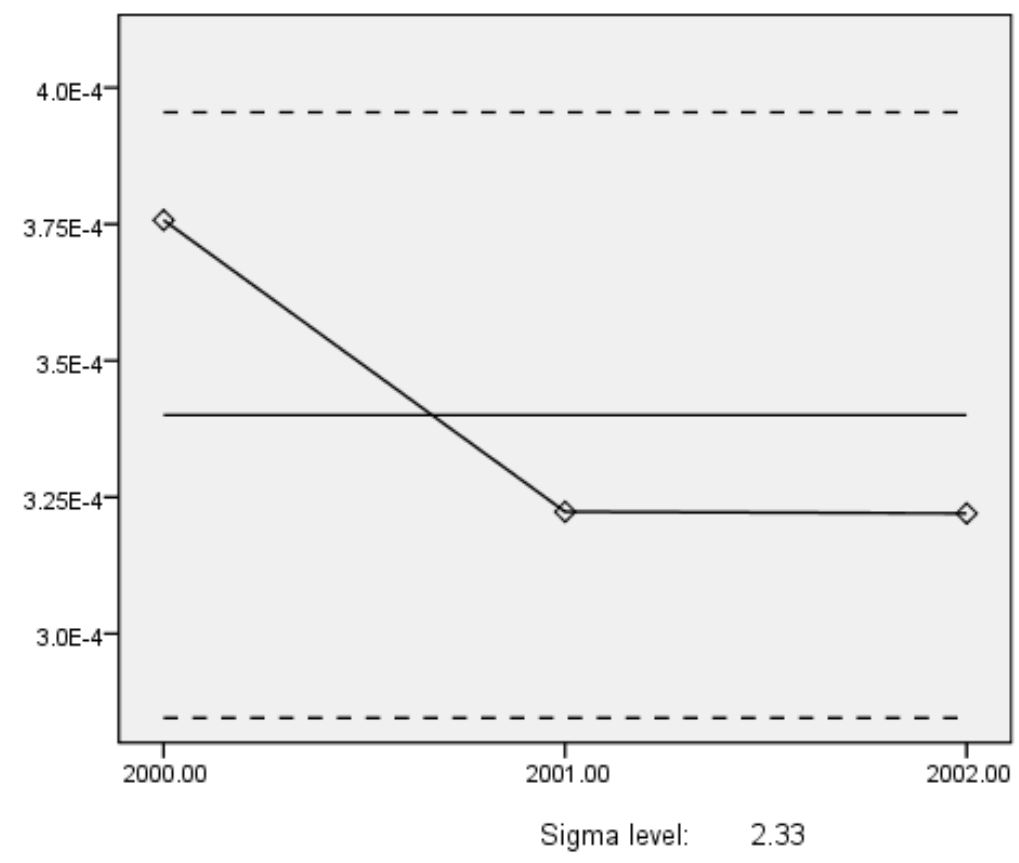

- R3

-.UCL $=.0004$

- - Average $=.0003$

- - $\mathrm{LCL}=.0003$

Figure 1. R(3) control chart for the Philippines.

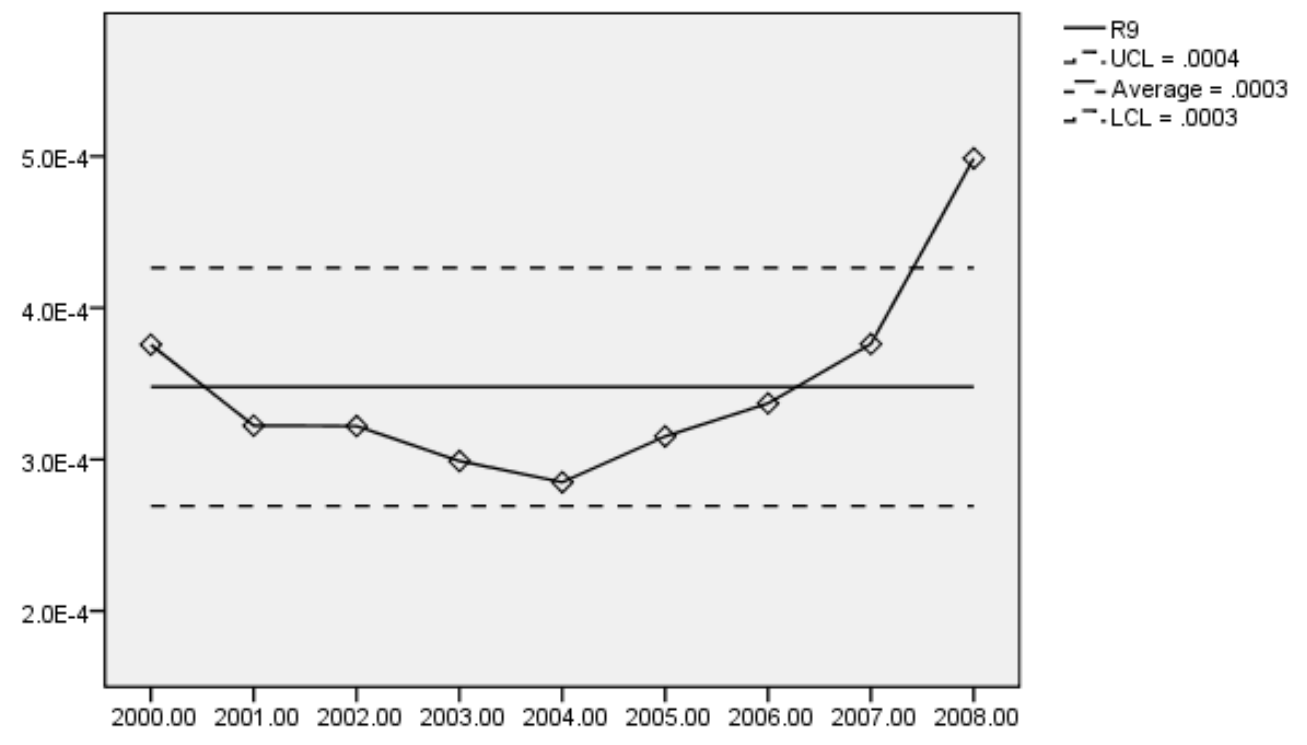

Sigma level: $\quad 2.33$

Figure 2. $R(9)$ control chart for the Philippines. 
Table 2. Restlessness in the Philippines.

\begin{tabular}{|c|c|c|c|c|c|c|c|c|c|}
\hline \multirow{2}{*}{ Country } & \multicolumn{2}{|c|}{ Restless } & \multirow{2}{*}{ Restless ( $n$ ) } & \multirow{2}{*}{$\begin{array}{c}\text { Un- } \\
\text { Precedented }\end{array}$} & \multirow{2}{*}{ Crisis } & \multirow{2}{*}{$\begin{array}{c}\text { Out of } \\
\text { Control and } \\
\text { Crisis }\end{array}$} & \multirow{2}{*}{$\begin{array}{l}\text { In Control } \\
\text { and Crisis }\end{array}$} & \multirow{2}{*}{$\begin{array}{c}\text { Out of } \\
\text { Control and } \\
\text { No Crisis } \\
\end{array}$} & \multirow{2}{*}{$\begin{array}{c}\text { In Control } \\
\text { and No } \\
\text { Crisis }\end{array}$} \\
\hline & Year & $\mathbf{R}$ & & & & & & & \\
\hline \multirow{13}{*}{ Philippines } & 2000 & 0.000375746 & $\mathrm{R}(3)$ & & & & & & V \\
\hline & 2001 & 0.000322328 & $\mathrm{R}(4)$ & & & & & & V \\
\hline & 2002 & 0.000322021 & $\mathrm{R}(5)$ & & & & & & V \\
\hline & 2003 & 0.000298961 & $\mathrm{R}(6)$ & & & & & & V \\
\hline & 2004 & 0.000284962 & $\mathrm{R}(7)$ & & & & & & V \\
\hline & 2005 & 0.000315249 & $\mathrm{R}(8)$ & & & & & & V \\
\hline & 2006 & 0.00033701 & $\mathrm{R}(9)$ & V & $\mathrm{V}$ & $\mathrm{V}$ & & & \\
\hline & 2007 & 0.000376223 & $\mathrm{R}(10)$ & & & & & & V \\
\hline & 2008 & 0.000498668 & $\mathrm{R}(11)$ & & & & & & $\mathrm{V}$ \\
\hline & 2009 & 0.000486401 & $\mathrm{R}(12)$ & & & & & & V \\
\hline & 2010 & 0.000486944 & $\mathrm{R}(13)$ & & & & & & V \\
\hline & 2011 & 0.000504836 & & & & & & & \\
\hline & 2012 & 0.000501211 & & & & & & & \\
\hline
\end{tabular}

\subsection{Success Probability (SP)}

The probability of success is a concept closely related to conditional power and predictive power. Conditional power is the probability of observing statistical significance given the observed data and assuming the treatment effect parameter equals a specific value [22]. In confusion matrix theory, $S P$ is the value of precision or the positive predictive value (PPV). The $S P$ is calculated to see how many predictions of an event really match the occurrence of that event, then to compare this to the sum of all the event predictions. The purpose of the success probability or PPV is to see the proportion of correct event predictions in order to describe the precision of the predictions. A $100 \% S P$ value means that all event predictions generated by the classifier precisely match the actual event occurrence, so a large $S P$ value provides confidence that the predicted result is accurate.

Success probability in this paper is formulated by:

$$
S P=\frac{a}{C_{1}}
$$

\subsection{Constraint Probability $(C P)$}

In confusion matrix theory, $C P$ is referred to as the recall value, sensitivity, or the true positive rate (TPR). $C P$ is calculated to see how many event predictions really match the occurrence of an event, then to compare this to the sum of actual events. The purpose of the constraint probability or sensitivity is to see the proportion of actual events that are correctly predicted; it describes the sensitivity of the indicator or classifier used, whereby a $100 \%$ sensitivity value means that all actual events are correctly predicted by the classifier [2] The process must hunt for outliers until all outlier data are valid, as represented by an acceptable number of false alarms [23].

The constraint probability is formulated as follows:

$$
C P=\frac{a}{R_{1}}
$$

If both conditions are fulfilled, this means that the UR indicator has good sensitivity to detect the occurrence of rice crises through the value of restlessness, and the resulting estimate can be said to be accurate or precise. It can be concluded that the UR indicator is valid as an indicator of rice crises at country the level; however, if one or both conditions are not fulfilled, this means that the UR indicator still lacks accuracy in prediction and cannot be an indicator of rice crises. The interpretation of $S P$ and $C P$ values is subjective, 
meaning the $S P$ and $C P$ validity criteria can be interpreted in accordance with the user subjectivity of the UR indicator.

The terminology and derivations from the confusion matrix according to Tharwat are outlined below [24].

Condition positive $(\mathrm{P})$ is the number of real positive cases in the data, while condition negative $(\mathrm{N})$ is the number of real negative cases in the data. The true positive (TP) is the equivalent true negative (TN) with correct rejection for the equivalent false positive (FP) with false alarms, including type I error false negative (FN) and type II errors [24]. Given a classifier and an instance, there are four possible outcomes. If the instance is positive and it is classified as positive, it is counted as a true positive; if it is classified as negative, it is counted as a false negative. If the instance is negative and it is classified as negative, it is counted as a true negative; if it is classified as positive, it is counted as a false positive. Given a classifier and a set of instances (the test set), a two-by-two confusion matrix (also called a contingency table) can be constructed, representing the dispositions of the set of instances. This matrix forms the basis for many common metrics [25]. Receiver operating characteristics (ROC) graphs are used for visualizing, organizing, and selecting classifiers based on their performance. ROC graphs have long been used in signal detection theory to depict the tradeoff between the hit rates and false alarm rates of classifiers [26]. Numerous studies exist in the medical decision-making community on the use of ROC graphs for diagnostic testing [25]. Zuo used ROC graphs for diagnostic testing [27]. Swets et al. (2000) brought ROC curves to the attention of the wider public with their Scientific American article [28].

Unprecedented analysis is done using a modified I-chart without an outlier removal procedure. Individual control charts are used when there is only one individual unit in each observation sample [29]. As with other control charts, the individual charts consist of points plotted with the control limits or natural process limits. These limits reflect what the process will deliver without a fundamental characteristic of risk [30]. The normal distribution is not assumed nor required in the calculation of the control limits, making the individual chart a very robust tool. This was demonstrated by Wheeler using real-world data [31,32] and for a number of highly non-normal probability distributions [33]. In some cases, it may be advisable to use the median of the moving range rather than its average, as when the calculated range data contain a few large values, this may inflate the estimate of the population's dispersion [34]. Using the modified I-chart without the outlier removal procedure, the combination of $n=10$ and $\mathrm{L}=3.20$ results in SP 0.31 and $C P$ 0.57. The validity of unprecedented restlessness in indicating a rice crisis is $31 \%$. What can we conclude from this? How do we interpret the results of the SP and CP discussed earlier? Is it sufficient if $S P$ and $C P$ exceed 0.5 ? It must be recognized that not all events with a probability below $50 \%$ are unreliable and not all events with a probability above $50 \%$ should be trusted. In certain cases, a probability of $70 \%$ is too low.

In this context, we would like to propose a calculated risk approach that is different than the subjective method. In the subjective method, researchers set success criteria based on the coefficient of confidence. Probability levels of $95 \%$ and $99 \%$ are success criteria that are commonly used by researchers. In this study, we develop a new approach, where the success criteria are calculated objectively based on the risk calculation.

\subsection{Problem Formulation}

Based on the aforementioned background, it can be seen that the determination of $S P$ and $C P$ values is subjective. Therefore, the current issues concerning the validity of the unprecedented restlessness rice crisis indicator cannot be identified because the decision regarding the validity of this indicator is not objective. This fact shows that objective criteria are needed to determine the validity of rice crisis indicators.

A previous study addressed the issue of improvement in unprecedented restlessness as an indicator of national-level rice crises. This study aimed to identify objective criteria that can be used to determine the validity of the unprecedented restlessness indicator [11]. 


\subsection{Research Objective}

The purpose of this study is to develop a model for determining objective criteria in order to assess the validity of the indicator of unprecedented restlessness.

The output of this research is to obtain a model for determining the objective success probability. The procedure used to establish the right, valid, and reliable model is the main problem in modeling [21]. The mathematical model is a reliable and efficient tool [35].

This result is a breakthrough, as it is different from the standard practice used so far in statistics, whereby the success probability is always set in a subjective way. The commonly used standard practice is to set a success probability level of 0.95 or 0.99 . This is a subjective parameter in scientific practice that must be immediately reduced.

\subsection{Scope of Study}

This study limits the analysis to the determination of objective methods for selecting success criteria for indicators of unprecedented restlessness based on rice price producers.

\subsection{Benefits of Research}

The theoretical benefit of this study is the scientific contribution to the determination of objective success probability criteria.

The practical benefit of this study is that success criteria can be set accurately according to the context of the problem; thus, these criteria can be used as substitutes for the common practice of setting a success probability of 0.95 or 0.99 , which can result in overestimated or underestimated values.

\section{Methodology for Determining the Importance of the Rice Crisis Indicator}

\subsection{Risk Management}

Risk management is the identification, evaluation, and prioritization of risks and the economical application of resources to minimize, monitor, and control the probability or impacts of unfortunate events [36]. Mandelbrot distinguished between "mild" and "wild" risks and argued that risk assessment and management approaches must be fundamentally different for the two types of risk [37]. As such, there are three main questions related to risk management, namely what is the risk, what is causing the risk, and how can the risk be mitigated.

We define a risky event as any event that is not known for sure ahead of time. This gives some hints as to the basic characteristics of risk. First, this rules out affirmative events (e.g., events that have already occurred and have been observed). Second, it suggests that time is a fundamental characteristic of risk. Indeed, by allowing room for learning, some events that are not known today may become known tomorrow (e.g., rainfall in a particular location). This stresses the temporal dimension of risk. The prevalence of risky events means that there are many things that are not known currently. On the one hand, this stresses the importance of assessing these risky outcomes in making decisions under conditions of uncertainty. On the other hand, this raises a serious issue, namely how do individuals deal with extensive uncertainty found in their environment? Attempting to rationalize risky events can be in conflict with scientific beliefs, whereby any event can be explained in a cause-effect framework. In this context, one could argue that scientific belief denies the existence of risk; if so, why are there risky events? There are three main factors that contribute to the existence and prevalence of risky events. First, risk exists occur because of our inability to precisely control or measure certain causal factors of events. A good example (commonly used in teaching probability) is the outcome of flipping a coin. Ask a physicist or an engineer if there is anything that is not understood in the process of flipping a coin and the answer will be no. The objective of a risk analysis, both in theory and in practice, is to present this analytical framework and to illustrate how it can be used to investigate economic decisions under risk conditions. In a sense, the economics of risk is a difficult subject: it involves understanding human decisions in the absence of perfect information. How do we make decisions when we do not know that some of the 
events affect us? The complexities of our uncertain world and of how humans obtain and process information make this difficult. In spite of these difficulties, much progress has been made. First, probability theory is the cornerstone of risk assessment. This allows us to measure risk in a fashion that can be communicated among decision makers or researchers. Second, risk preferences are now better understood. This provides useful insights into the economic rationality of decision-making under conditions of uncertainty. Third, in recent decades, good insights have been shown regarding the value of information, allowing a better understanding of the role of information in human decision-making. The analysis approach present here allows systematic treatment of these issues in the context of both private and public decisions under conditions of uncertainty [38].

\subsection{Framework of the Study}

Subjective versus Objective Success Criteria

Success criteria can be set objectively and accurately according to the context of the problem. This is why this criterion becomes a substitute for the common practice of setting a success probability of 0.95 or 0.99 subjectively, which can result in overestimated or underestimated values.

\subsection{Risk Analysis}

The framework for this method is based on the concept of prevention or anticipation and recovery, so the basic question is to ask which costs more, anticipation or recovery? The basic argument for integrating disaster awareness into development planning is that it is wasteful not to do so. By and large, developed nations choose disaster prevention over recovery [39]. A well-known saying is, "a stitch in time saves nine", the meaning of which is that if you see a small problem and solve it early, you will prevent it from becoming a big problem later. This begs the question, which is more cost-effective for a developing country, disaster prevention or disaster recovery? What choices do governments of disaster-prone developing countries face as they adopt programs for economic and social development and try at the same time to manage losses and suffering from natural disasters? What are the implications for long-term prevention versus recovery? What are the costs and benefits of approaches governments - and donors - must consider as they decide when, where, and how much of their resources to allocate for disaster response?

In weighing these options, cost-benefit analysis methods that acknowledge and assess the actual outcomes of different courses of action are preferable to those that "handle" them via mathematical manipulation. A cost-benefit analysis (CBA), sometimes also called a benefit-cost analysis, is a systematic approach to estimating the strengths and weaknesses of alternatives used to determine options that provide the best approach to achieving benefits while preserving savings (for example, in transactions, activities, and functional business requirements) [40]. A CBA helps predict whether the benefits of a policy outweigh its costs (and by how much), relative to other alternatives. This allows the ranking of alternative policies in terms of a cost-benefit ratio [41]. Although a CBA can offer an informed estimate of the best alternative, a perfect appraisal of all present and future costs and benefits is difficult; perfection, in terms of economic efficiency and social welfare, is not guaranteed [42]. The value of a cost-benefit analysis depends on the accuracy of the individual cost and benefit estimates. Comparative studies indicate that such estimates are often flawed [43]. Interest groups may attempt to include (or exclude) significant costs in an analysis to influence its outcome [44].

Based on the way of thinking described above, studies are formulated as follows. The subjective success criterion raises the question of why the success score is set at 0.6 . A $31 \%$ validity score is shown for unprecedented restlessness in indicating rice crisis. What can we conclude from this? How do we interpret the results of these SP and CP? Is it enough if the SP and CP exceed 0.5? It must be recognized that not all events with a probability below $50 \%$ are unreliable and not all events with a probability above $50 \%$ should be trusted. For a particular event, a probability of $70 \%$ may be too low. In this context, we would like 
to propose a calculated risk approach as a substitute for determining subjective values such as $50 \%, 60 \%$, and so on. This means that the success criteria must be determined based on risk calculations; therefore, in this this study we focus on risk analysis. We must calculate the costs of wrong decisions caused by both believing and not believing in the success probability. If risk losses caused by believing in the $31 \%$ success probability are greater than risk losses caused by not believing in it, then the choice that has to be made is the first one (believing in it). This is why in this research we recommend a new approach for determining the success criteria of an indicator. Usually, a success criterion is determined by a number, e.g., 0.5, which indicates exceeding the event by chance. In our research framework, the success criteria for an indicator are stated on the basis of a risk analysis. This implies the need to measure the decision by taking risks. The descriptions for the risk analysis are outlined below.

The probability of a rice crisis event occurring one year later is $30 \%$. This means that from 10 prediction experiments (recurring assumptions), 3 predictions were true and 7 turned out to be false alarms. If faced against such predictive performance, the choices of action are to either stay silent (not believe), do not care about the warning given by the crisis indicator, and do not think about the consideration that is the basis of this silent action; or take a precaution (believe) when an alarm sounds and think about the consideration that is the basis for this precautious action.

Both actions have risk consequences. There is a risk to be taken into account when deciding to be silent, regardless of the UR indicator warning. The risk is that the UR correctly indicates a rice crisis incident. On the other hand, the risk of ignoring the UR indicators by performing preventive action is an incorrect UR; that is, nothing happens and there is no rice crisis.

If the second action is taken, then there is a preventive action because the crisis explodes, with the consequence of a loss or profit opportunity. If the first action is taken and people continue to carry out routine activities, accompanied by benefiting from the achievement of the target, they must be ready to face the consequences of large losses caused by an exploding rice crisis, which can result in human suffering. Understanding the risks of each action will allow us to discuss the risk calculations.

\section{Data, Source, and Technique}

\subsection{Data Collection}

Based on previous research [35], it was found that 43 countries have similarities with Indonesia based on the democratic atmosphere, rice consumption, and rice purchasing power. Eleven of these countries implemented recovery policies in response to a rice crisis, meaning that crisis recovery cost (CRC) or riot recovery cost were budgeted, while the remaining 32 countries implemented policies of prevention, or a crisis anticipation cost (CAC), in response to the threat of rice crises, as reflected in the budget for anticipation costs. The global data sources were searched comprehensively, including the World Bank, Food Agriculture Organization, and International Rice Research Institute (IRRI) databases. Tables 3 and 4 shows an overview of the recovery costs for 11 countries and the anticipation costs for 32 countries. 
Table 3. Total costs of recovery policy (US\$) in crisis countries.

\begin{tabular}{ccc}
\hline No. & Country Name & Total (US\$) \\
\hline 1 & Bangladesh & $123,719,841$ \\
\hline 2 & Côte d'Ivoire & $1,835,176,337$ \\
\hline 3 & Haiti & $276,198,444$ \\
\hline 4 & India & $288,215,492$ \\
\hline 6 & Peru & $27,665,011$ \\
\hline 7 & Philippines & $3,943,561,228$ \\
\hline 8 & Senegal & $1,446,264,709$ \\
\hline 9 & Guinea & $2,744,623$ \\
\hline 10 & Madagascar & $3,900,000$ \\
\hline 11 & Gambia & $88,440,000$ \\
\hline
\end{tabular}

Further assessment of the recovery and anticipation costs in these two groups of countries was carried out by testing the difference between the two independent populations. These cases contain sample values of a cost variable from the two populations. The countries that apply a recovery policy comprise group 1 and the countries that implement a prevention policy comprise group 2; therefore, a test can be performed to assess the difference between the means of these populations. In the hypothesis test, null hypothesis $\mathrm{H} 0$, which states that the means for both groups are equal, is tested against the alternative hypothesis H1, which states that the means are not equal. The Kruskal-Wallis non parametric test is conducted based on the rank of all observations, as shown in Table 5.

Table 4. Total costs of anticipation policy (US\$) in 32 non-crisis countries.

\begin{tabular}{|c|c|c|}
\hline No. & Country Name & Total (US\$) \\
\hline 1 & Costa Rica & $3,012,444$ \\
\hline 2 & Cuba & $14,360,181$ \\
\hline 3 & Djibouti & 28,863 \\
\hline 4 & Dominican Republic & $2,309,554$ \\
\hline 6 & Fiji & $1,111,488$ \\
\hline 7 & China, Hong Kong SAR & 536,437 \\
\hline 8 & Jamaica & $2,919,918$ \\
\hline 9 & Liberia & $6,000,000$ \\
\hline 10 & China, Macao SAR & 28,398 \\
\hline 11 & Mali & $41,115,716$ \\
\hline 12 & Nepal & $1,756,487$ \\
\hline 13 & Sri Lanka & 88,393 \\
\hline 14 & Oman & $4,800,501,133$ \\
\hline 15 & Kuwait & 533,554 \\
\hline 16 & Brazil & $6,470,746,422$ \\
\hline 17 & Cambodia & 14,888 \\
\hline 18 & China & $1,044,980$ \\
\hline 19 & Ecuador & 2,631 \\
\hline 20 & Guinea-Bissau & 969,894 \\
\hline
\end{tabular}


Table 4. Cont.

\begin{tabular}{ccc}
\hline No. & Country Name & Total (US\$) \\
\hline 21 & Indonesia & $8,492,772,938$ \\
\hline 22 & Japan & $1,045,252$ \\
\hline 23 & Korea, Dem. Rep. & 65,700 \\
\hline 24 & Republic of Korea & $6,000,448,395$ \\
\hline 25 & Lao People's Democratic & 14,556 \\
\hline 26 & Republic & $16,544,422$ \\
\hline 27 & Nicaragua & 14,556 \\
\hline 28 & Panama & 285 \\
\hline 29 & Suriname & $1,269,763,103$ \\
\hline 30 & Thailand & 200,000 \\
\hline 31 & Viet Nam & - \\
\hline 32 & United Arab Emirates & $9,603,305,000$ \\
\hline & Malaysia & $4,800,000,000$ \\
\hline
\end{tabular}

Table 5. Total anticipation policy (US\$) costs for 32 non-crisis countries.

\begin{tabular}{|c|c|c|c|}
\hline No. & Policy & $\mathbf{N}$ & Mean Rank \\
\hline \multirow{2}{*}{ Cost } & Recovery Cost & 11 & 30.00 \\
\hline & Prevention Cost & 32 & 19.25 \\
\hline \multicolumn{2}{|c|}{ Total } & 43 & \\
\hline
\end{tabular}

Table 6 presents the sampling distribution for the Kruskal-Wallis test, involving a chi-squared distribution with $\mathrm{k}-1$ degrees of freedom, corresponding to $2-1=1$ degrees of freedom in this study. The software shows a $p$-value of 0.014 and a $5 \%$ risk, indicating that the mean costs for the two groups are unequal.

Table 6. Test statistics ${ }^{\mathrm{a}, \mathrm{b}}$ for differences between the two groups.

\begin{tabular}{cc}
\hline & Cost \\
\hline Chi-Square & 6.000 \\
\hline $\mathrm{df}$ & 1 \\
\hline Asymp. Sig. & 0.014
\end{tabular}

a: Kruskal Wallis Test has been used to test the mean difference between the two groups; b: Grouping Variable: POLICY. The two groups are group 1 consisting of countries that implement recovery policies while group 2 are countries that implement preventive or anticipative policies.

The results of this analysis are reinforced by the data in Table 7, which show that the average recovery cost of $\$ 731,410,130.910$ is much smaller than the average anticipation cost of $\$ 1,297,851,737.130$. Based on these facts, the crisis recovery cost (CRC) to crisis anticipation cost (CAC) ratio for the 43 countries is 0.57 .

Table 7. Kruskal-Wallis test for the two groups of countries.

\begin{tabular}{ccc}
\hline Mean & Std. Deviation & Std. Error Mean \\
\hline $731,410,130.910$ & $1,237,336,781.709$ & $373,071,076.749$ \\
\hline $1,297,851,737.130$ & $2,759,292,417.459$ & $487,778,594.915$ \\
\hline
\end{tabular}




\subsection{Sample Design}

The units of analysis in this study were the crisis recovery cost (CRC) and crisis anticipation cost (CAC) for all 43 countries with the same characteristics as Indonesia in terms of rice consumption patterns. The sample selection of 43 countries was determined through the results of the study [45].

\subsection{Data Processing and Analysis}

Processing and data analysis were conducted by following the methodology for determining the importance of the rice crisis indicator as described in the following section.

\subsection{The Importance of the Rice Crisis Indicator}

From the previous analysis, it was known that in order to be considered important, the crisis recovery cost (CRC) to crisis anticipation cost (CAC) ratio should be greater than 7 for the indicator, with an accuracy probability of $30 \%$. This was known from the empirical data analysis on the distribution of the crisis recovery cost and crisis anticipation cost and their parameters. This was done because this study did not limit the results only to descriptive statistics by only calculating the CRC-to-CAC ratio, which would lead to misleading conclusions. This study was, therefore, expanded by covering the inferential statistics, meaning we had to identify the distributions of the crisis recovery cost (CRC) and crisis anticipation cost (CAC) for the 43 countries with the same pattern of rice consumption as Indonesia.

It was also known from the empirical data analysis that the crisis recovery cost follows a gamma distribution with $\alpha=0.48$ and $\beta=0.68$, while the crisis anticipation cost follows a gamma distribution with $\alpha=0.48$ and $\beta=0.68$.

The next step involves calculating the probability of the CRC-to-CAC ratio having a value greater than 7 . To do so, the following steps are performed:

\subsection{Sample CRC Distribution}

- Generate 800 equally spaced numbers between 0 and 0.8 (the probability of the CRC having values greater than 0.8 is neglectable);

- Calculate the probability of each number using the following formula:

$$
\mathrm{Gr}(\mathrm{X} 1)=\mathrm{GammaDist}(\mathrm{X} 1 ; 0.48 ; 0.68 ; \mathrm{TRUE})
$$

$\operatorname{Gr}(X \mathrm{X})=\operatorname{GammaDist}(\mathrm{Xi} ; 0.48 ; 0.68 ; \mathrm{TRUE})$-GammaDist $(\mathrm{X}[\mathrm{i}-1]$; 0.48; 0.68; TRUE) for I > 1 where $\mathrm{Gr}(\mathrm{Xi})$ is the probability of $\mathrm{Xi}$; GammaDist is the Microsoft Excel function for the gamma distribution; $\mathrm{X} 1, \mathrm{X} 2, \mathrm{X} 3, \ldots, \mathrm{X} 800$ are ordered numbers generated in the previous step.

\subsection{Sample CAC Distribution}

- Generate 800 equally spaced numbers between 0 and 0.3 (the probability of the CAC having values greater than 0.3 is neglectable);

- Calculate the probability of each number between 0 and 0.3 using the following formula:

$$
\mathrm{Ga}(\mathrm{Y} 1)=\operatorname{GammaDist}(\mathrm{Y} 1 ; 0.48 ; 0.68 ; \mathrm{TRUE})
$$

$\operatorname{Gr}(Y i)=\operatorname{GammaDist}(Y i ; 0.48 ; 0.68$; TRUE) -GammaDist(Y[i - 1]; 0.48; 0.68; TRUE) for I > 1 where $\mathrm{Ga}(\mathrm{Yi})$ is the probability of $\mathrm{Yi} ; \mathrm{Y} 1, \mathrm{Y} 2, \mathrm{Y} 3, \ldots, \mathrm{Y} 800$ are ordered numbers generated in the previous step.

\subsection{Generate the Probability Distribution of the CRC-to-CAC Ratio}

The probability distribution of the CRC-to-CAC ratio is calculated as follows:

$$
\mathrm{P}(\mathrm{Z})=\sum_{\mathrm{n}} \sum_{\mathrm{m}}(\mathrm{m}, \mathrm{n}, \mathrm{Z}) ; 1 \leq \mathrm{m} \leq 800 ; 1 \leq \mathrm{n} \leq 800 ;
$$


where $\mathrm{Z}$ is the $\mathrm{CRC}$-to-CAC ratio and the function $\mathrm{T}(\mathrm{m}, \mathrm{n}, \mathrm{Z})$ is defined as follows:

$$
\begin{gathered}
\mathrm{T}(\mathrm{m}, \mathrm{n}, \mathrm{Z})=0 \text { if } \mathrm{Xm} / \mathrm{Yn} \neq \mathrm{Z} \\
\mathrm{T}(\mathrm{m}, \mathrm{n}, \mathrm{Z})=\mathrm{Gr}(\mathrm{Xm}) * \mathrm{Ga}(\mathrm{Yn}) \quad \text { if } \mathrm{Xm} / \mathrm{Yn}=\mathrm{Z}
\end{gathered}
$$

\subsection{Calculate the Probability of the CRC-to-CAC Ratio Having a Value Greater than 7}

The probability of the CRC-to-CAC ratio having a value greater than 7 is calculated as follows:

$$
\mathrm{PZ}>7=1-\mathrm{PZ} \leq 7 .
$$

This means that if the recovery cost is greater than 7 times the anticipation cost, then this indicator is important, where:

$$
\mathrm{PZ} \leq 7=\sum_{\mathrm{u}} \mathrm{Q}(\mathrm{Zu})
$$

where:

$$
\begin{gathered}
1 \leq \mathrm{u} \leq|\mathrm{H}| \\
\mathrm{Zu} \in \mathrm{H} \\
\mathrm{H}=\{\mathrm{Xi} / \mathrm{Yj} \mid 1 \leq \mathrm{i} \leq 800 ; 1 \leq \mathrm{j} \leq 800 ; \mathrm{Xi} / \mathrm{Yj} \leq 7\}
\end{gathered}
$$

After following these steps, it was found that the probability of the CRC-to-CAC ratio having a value greater than 7 was 0.76 , meaning that the CRC-to-CAC ratio tends to be higher than 7.

\section{Conclusions}

1. Based on the risk analysis and by calculating the probability of the CRC-to-CAC ratio having values greater than 7 , unprecedented restlessness, which has been defined as a rice crisis indicator at the national level, is an important indicator. Its validity was verified using a modified I-chart without an outlier removal procedure. After tedious computation, the combination of values of $n=10$ and $\mathrm{L}=3.20$ gave values for the success probability of 0.31 and for the constraint probability of 0.57 ;

2. An unprecedented event is something that has never been experienced before and is a cause for worry. Unprecedented restlessness (UR) is a strong indicator of a rice crisis at national level, which means if there is unprecedented restlessness then it will be immediately followed by a rice crisis; conversely, if there is not then there will be no rice crisis;

3. The unprecedented restlessness indicator can be used in alternative monitoring systems to enable the detection of rice crises at the national level. This means that UR can be used to assess the effectiveness of a country's agricultural strategy. If UR does not show up, the agricultural strategy is considered effective, and vice versa. Notice that restlessness ( $\mathrm{R}$ ) is not an indicator of rice crises; $\mathrm{R}$ is the measure of life burden, because if the $R$ increases over time in a country then food is becoming harder to obtain in that country. In other words, the higher the $\mathrm{R}$ value, the greater the life burden.

Author Contributions: Conceptualization, Y.H. and S. (Sukono); methodology, D.R.; software, S. (Subiyanto) and J.S.; validation, T.P.; formal analysis, Y.H.; investigation, T.P.; data curation, T.P.; writing — original draft preparation, Y.H.; writing—review and editing, Y.H. and S. (Subiyanto); visualization, S. (Subiyanto); supervision, S. (Sukono); project administration, Y.H. and D.R.; funding acquisition, Y.H.; Resources, J.S. All authors have read and agreed to the published version of the manuscript.

Funding: This research received no external funding. 
Acknowledgments: The authors are grateful to the constructive comments from three anonymous reviewers. The author would also like to thank the Dean of the Faculty of Mathematics and Natural Sciences, Universitas Padjadjaran, and the Directorate of Research and Community Service (DRPM).

Conflicts of Interest: The authors declare no conflict of interest.

\section{References}

1. Erokhin, V.; Gao, T. Impacts of COVID-19 on trade and economic aspects of food security: Evidence from 45 developing countries. Int. J. Environ. Res. Public Health 2020, 17, 5775. [CrossRef]

2. Cuesta, J.; Htenas, A.; Tiwari, S. Monitoring global and national food price crises. Food Policy 2014, 49, 84-94. [CrossRef]

3. Jones, A.D.; Ngure, F.M.; Pelto, G.; Young, S.L. What are we assessing when we measure food security? A compendium and review of current metrics. Adv. Nutr. 2013, 4, 481-505. [CrossRef]

4. Global Partners, I.P.C. Integrated food security phase classification technical manual version 2.0. In Evidence and Standards for Better Food Security Decisions; FAO: Rome, Italy, 2012.

5. Cissé, H. Should the Political Prohibition in Charters of International Financial Institutions Be Revisited: The Case of the World Bank. World Bank Legal Rev. 2012, 3, 59.

6. Leaning, J.; Guha-Sapir, D. Natural disasters, armed conflict, and public health. N. Engl. J. Med. 2013, 369, 1836-1842. [CrossRef] [PubMed]

7. Hirschman, A.O. A generalized linkage approach to development, with special reference to staples. Econ. Dev. Cult. Chang. 1977, $25,67$.

8. Strategic Framework 2025: Work Programme 2012-2015, with Addendum on Budget Requirements for 2012-2013. Available online: https: / / www.unisdr.org/files/23291_1101657inteng.pdf (accessed on 17 October 2020).

9. Hillbruner, C.; Moloney, G. When early warning is not enough-Lessons learned from the 2011 Somalia Famine. Glob. Food Secur 2012, 1, 20-28. [CrossRef]

10. Devereux, S. Distinguishing between Chronic and Transitory Food Insecurity. In Needs Assessments; IDS for WFP: Rome, Italy, 2006.

11. Hidayat, Y.; Purwandari, T.; Sukono, S.; Supian, S.; Juahir, H.; Kamarudin, M.K.A.; Yusra, A.I. Improving unprecedented restlessness as the new strong indicator of rice crisis at national level. J. Fundam. Appl. Sci. 2018, 10, 128-138.

12. Schneider, M. We Are Hungry! A Summary Report of Food Riots, Government Responses, and States of Democracy in 2008, Working Paper. 2008. Available online: citeseerx.ist.psu.edu/viewdoc/citations?doi=10.1.1.527.1678 (accessed on 11 June 2021).

13. Brown, M.E.; Brickley, E.B. Evaluating the use of remote sensing data in the US Agency for International Development Famine Early Warning Systems Network. J. Appl. Remote Sens. 2003, 6, 063511.

14. Headey, D.; Fan, S. Anatomy of a crisis: The causes and consequences of surging food prices. Agric. Econ. 2008, 39, 375-391. [CrossRef]

15. Nomaguchi, K.M.; Milkie, M.A. Costs and rewards of children: The effects of becoming a parent on adults' lives. J. Marriage Fam. 2003, 65, 356-374. [CrossRef]

16. Sukono, H.Y.; Bon, A.T.B.; Supian, S. Modelling of Capital Asset Pricing by Considering the Lagged Effects. Mater. Sci. Eng. 2017, 166, 12001. [CrossRef]

17. Gorunescu, F. Data Mining: Concepts, Models and Techniques; Springer Science \& Business Media: Berlin/Heidelberg, Germany, 2011; Volume 12.

18. Stehman, S.V. Selecting and interpreting measures of thematic classification accuracy. Remote. Sens. Environ. 1997, 62, 77-89. [CrossRef]

19. Rea, C.; Granetz, R.S.; Montes, K.; Tinguely, R.A.; Eidietis, N.; Hanson, J.M.; Sammuli, B. Disruption prediction investigations using machine learning tools on DIII-D and Alcator C-Mod. Plasma Phys. Control. Fusion 2018, 60, 084004. [CrossRef]

20. Chicco, D.; Jurman, G. The advantages of the Matthews correlation coefficient (MCC) over F1 score and accuracy in binary classification evaluation. BMC Genom. 2020, 21, 1-13. [CrossRef] [PubMed]

21. Hidayat, Y.; Sutijo, B.; Bon, A.T.; Supian, S. Indonesian financial data modeling and forecasting by using econometrics time series and neural network. Glob. J. Pure Appl. Math. 2016, 12, 3745-3757.

22. Tang, Z. Optimal futility interim design: A predictive probability of success approach with time-to-event endpoint. J. Biopharm. Stat. 2015, 25, 1312-1319. [CrossRef] [PubMed]

23. Hidayat, Y.; Purwandari, T.S.S. Identifying Unwanted Conditions through Chaotic Area Determination in the Context of Indonesia's Economic Resilience at the City Level. Sustainability 2021, 13, 5183. [CrossRef]

24. Tharwat, A. Classification assessment methods. Appl. Comput. Inform. 2020. [CrossRef]

25. Fawcett, T. An introduction to ROC analysis. Pattern Recognit. Lett. 2006, 27, 861-874. [CrossRef]

26. Wixted, J.T. The forgotten history of signal detection theory. J. Exp. Psychol. Learn. Mem. Cogn. 2020, 46, 201. [CrossRef] [PubMed]

27. Zou, K.H. Receiver Operating Characteristic (ROC) Literature Research. Available online: http://splweb.bwh.harvard.edu (accessed on 17 October 2020).

28. Swets, J.A.; Dawes, R.M.; Monahan, J. Better decisions through science. Sci. Am. 2000, 283, 82-87. [CrossRef] [PubMed]

29. Powers, D.M. Evaluation: From precision, recall and F-measure to ROC, informedness, markedness and correlation. arXiv 2020, arXiv:2010.16061. 
30. Watts, N.; Adger, W.N.; Ayeb-Karlsson, S.; Bai, Y.; Byass, P.; Campbell-Lendrum, D.; Costello, A. The Lancet Countdown: Tracking progress on health and climate change. Lancet 2017, 389, 1151-1164. [CrossRef]

31. Wheeler, D.J. When Can We Trust the Limits on a Process Behavior Chart; Quality Digest: Chico, CA, USA, 2009.

32. Wheeler, D.J. Good Limits from Bad Data; Quality Digest: Chico, CA, USA, 2009; p. 6.

33. Wheeler, D.J. Do You Have Leptokurtophobia; Quality Digest: Chico, CA, USA, 2009.

34. Wheeler, D.J. Individual Charts Done Right and Wrong; Quality Digest: Chico, CA, USA, 2010; p. 2.

35. Hidayat, Y.; Purwandari, T.; Ariska, Y.D. Countries population determination to test rice crisis indicator at national level using k-means cluster analysis. In IOP Conference Series: Materials Science and Engineering; IOP Science: Bristol, UK, 2017; Volume 166, p. 012023.

36. Njogo, B.O. Risk management in the Nigerian banking industry. Kuwait Chapter Arab. J. Bus. Manag. Rev. 2012, 1, 100.

37. Mandelbrot, B.B.; Hudson, R.L. The Behaviour of Markets: A Fractal View of Risk, Ruin and Reward; Profile Books: London, UK, 2010.

38. Walker, W.E.; Harremoës, P.; Rotmans, J.; Van Der Sluijs, J.P.; Van Asselt, M.B.; Janssen, P.; Krayer von Krauss, M.P. Defining uncertainty: A conceptual basis for uncertainty management in model-based decision support. Integr. Assess. 2003, 4, 5-17. [CrossRef]

39. Anderson, M.B. Which costs more: Prevention or recovery. In Managing Natural Disasters and the Environment; World Bank: Washington, DC, USA, 1991.

40. David, R.; Dube, A.; Ngulube, P. A Cost-Benefit Analysis of Document Management Strategies Used at a Financial Institution in Zimbabwe: A Case Study. South Afr. J. Inf. Manag. 2013, 15, 1-10. [CrossRef]

41. Browne, D.; Ryan, L. Comparative analysis of evaluation techniques for transport policies. Environ. Impact Assess. Rev. 2011, 31, 226-233. [CrossRef]

42. Martin, C.J.; McAdams, S.B.; Abdul-Muhsin, H.; Lim, V.M.; Nunez-Nateras, R.; Tyson, M.D.; Humphreys, M.R. The economic implications of a reusable flexible digital ureteroscope: A cost-benefit analysis. J. Urol. 2017, 197, 730-735. [CrossRef]

43. Song, F.; Altman, D.G.; Glenny, A.M.; Deeks, J.J. Validity of indirect comparison for estimating efficacy of competing interventions: Empirical evidence from published meta-analyses. BMJ 2003, 326, 472. [CrossRef] [PubMed]

44. Huesemann, M.; Huesemann, J. Techno-Fix: Why Technology Won't Save Us or the Environment; New Society Publishers: Gabriola Island, BC, Canada, 2011.

45. Hidayat, Y.; Subiyanto, M.F.; Ahmad, M.M.; Sambas, A.; Supian, S. Numerical simulation for identifying shoreline erosion in the vicinity of runway platform of Sultan Mahmud Airport, Kuala Terengganu, Malaysia. J. Eng. Appl. Sci. 2017, 12, 4617-4621. 